Diabetes

\section{Understanding the rising incidence of type 2 diabetes in adolescence}

\section{J Weill, S Vanderbecken, P Froguel}

\section{A focus on its epidemiology, pathology, and therapeutic consequences}

$\mathrm{T}$ he definition of diabetes mellitus (DM) was recently changed by the American Diabetes Association to a fasting plasma glucose value of at least $126 \mathrm{mg} / \mathrm{dl}(6.9 \mathrm{mmol} / \mathrm{l})$, on the basis of increased risk of the complication of retinopathy. ${ }^{1}$ It has been estimated that worldwide approximately 154 million people have diabetes, ${ }^{2}$ with up to one third of the cases remaining undiagnosed in developed countries such as the USA. Its human cost is considerable with morbidity from retinopathy, neuropathy, renal failure, and vascular disease, in addition to the socioeconomic burden. Additional lifetime health costs attributable to DM have been estimated at $£ 19649$ per affected individual in the UK. ${ }^{4}$

Since the introduction of insulin therapy, a clear distinction has been established between the form of DM where insulin is immediately needed (type 1 or insulin dependent DM), and that where there is a danger of hypoglycaemia, where insulin therapy represents a "luxury" (type 2 diabetes (T2D) or non-insulin dependent DM). The latter is far more frequently associated with obesity and a "gluttonous appetite". Age is a distinguishing feature: an age $\geqslant 40$ years predicts $\mathrm{T} 2 \mathrm{D}$ with a sensitivity of $97 \%$ and a specificity of $100 \%$.

However, nearly 25 years ago, North American authors first drew attention to the occurrence of T2D in young Pima Indians. ${ }^{7}$ Pinhas-Hamiel from Cincinnati highlighted the incidence of this condition in black adolescents; ${ }^{8}$ subsequently Hispano-American adolescents have been found to be affected. This concerned US health authorities sufficiently for the Centers for Disease Control and Prevention to order a specific committee to investigate. ${ }^{10}$

\section{EPIDEMIOLOGY}

In greater Cincinnati, the incidence of T2D among young people suddenly increased from 0.3-1.2/100 000 new cases per year before 1992 to $2.4 / 100000$ by 1994 (one third of all juvenile DM cases). Black adolescents, especially females were mainly affected, but whites were not spared. Almost all patients were overweight, but there was no apparent link between body mass index in obese individuals, and incidence. ${ }^{8}$ Prevalence rates were recently reassessed as $0.41 \%$ of teenagers in the USA, ${ }^{11}$ and more specifically, in a population of US obese adolescents and children, the prevalence of impaired glucose tolerance and silent T2D was estimated as $25 \%$ and $0.4 \%$ respectively, independent of ethnicity. ${ }^{12}$

In the Far East, the prevalence dramatically increased for Japanese schoolchildren between 1975 and 1980 from 1.3 to 6 per $100000 .{ }^{13}$ In UK (West Midlands and Leicester), eight T2D affected female teenagers were first identified from non-native ethnic minority groups-Pakistani, Indian, and Arabic, ${ }^{14}$ but recently Drake et al described in this journal the condition in four white significantly obese adolescents. ${ }^{15}$ Furthermore, in the southern hemisphere several cases have been found in obese adolescents on the islands of Polynesia and Réunion which are French Overseas Departments (P Froguel, unpublished data).

\section{PATHOLOGY}

In order to understand the mechanisms of T2D in adolescence, one has to take into account epidemiological data, ethnicity, and obesity, as well as puberty status and insulin secretion. There is a complex interplay of factors, essentially linked to lifestyle and genetics.

\section{Ethnicity}

Carbohydrate metabolism is influenced by ethnicity. For example, post-pubertal Mexicans show a bimodal glucose profile two hours after a glucose challenge. The first bell shaped distribution is seen in the majority, but a minority of the group have a separate, frankly diabetic curve. ${ }^{16}$ Resting energy expenditure and to a greater degree basal lipolysis are significantly lower in Afro-American prepubertal normal children than in their white counterparts. ${ }^{17} 18$

\section{Anthropometry and insulin resistance \\ Obesity}

Resistance to the hypoglycaemic action of insulin is a prerequisite to glucose intol- erance and T2D. ${ }^{12}$ Insulin resistance is more marked in normal black than normal white adolescents. ${ }^{19}$ Obesity causes, or at least, worsens insulin resistance, which is partially alleviated by diet induced slimming. ${ }^{20}$ Clinically, insulin resistance is shown by acanthosis nigricans, a velvety hyperpigmented cutaneous lesion, mainly located in the axillae and around the neck. ${ }^{15}$

The mechanism of insulin resistance in obesity is a matter of debate involving two confronting theories, metabolic and hormonal.

Metabolic: either endogenous or exogenous (supplied by food) nonesterified fatty acids, whose plasma levels are increased in obesity, antagonise glycolysis and thence glucose oxidation in skeletal muscles. ${ }^{21}$

Hormonal: obesity is characterised by an increase of plasma levels of adipocyte secreted diabetogenic hormones (leptin, cytokines such as tumour necrosis factor (TNF $\alpha$ ), interleukin 6, and resistin) and by the decrease of an insulin sensitising hormone, adiponectin. ${ }^{22}$

Insulin resistance is not universal in obesity, ${ }^{12}$ even in children with early onset and when it is severe. ${ }^{23} \mathrm{~T} 2 \mathrm{D}$ occurs when insulin secretion becomes unable to overcome the insulin resistance, ${ }^{12}$ resulting in variable insulin secretion defects, with a range of diabetes from silent to ketoacidosis. ${ }^{12} 24$

Intrauterine growth retardation Children born small for gestational age and remaining short are characterised by insulin resistance, ${ }^{25}$ which is a risk factor for T2D. This emphasises the important influence of intrauterine development on later health.

Fetal macrosomia

Conversely, in the offspring of mothers with diabetes from predisposed American Indian tribes, macrosomia is predictive of future T2D of youth. ${ }^{27}$

\section{Puberty}

Longitudinal studies have shown a drop in insulin sensitivity in late puberty, irrespective of changes in body fat, visceral fat, plasma insulin-like growth factor 1 , or sex steroid levels. ${ }^{27}$ This reduced insulin sensitivity is probably due to a sex hormone primed increase in growth hormone secretion. ${ }^{28}$

\section{Lifestyle}

Diet

The Japanese experience emphasises the role of saturated animal fats and proteins. The increase of juvenile T2D between 1975 and 1980 accompanied Westernisation of food, while the incidence of obesity progressed more slowly at that time. $^{13}$ Saturated fats promote 
obesity $^{29}$ and insulin resistance, ${ }^{21}$ and reduce insulin secretion by way of lipotoxicity, with hyperglycaemia exacerbating pancreatic beta cell damage by glucotoxicity. ${ }^{30}$

\section{Physical activity}

Physical training improves insulin sensitivity by increasing insulin dependent glucose transporter GLUT-4 expression in muscle. ${ }^{31}$ Furthermore, physical inactivity leads to an increased prevalence of obesity. ${ }^{32}$

\section{Toxicology}

Research from inner city Los Angeles minority patients with T2D showed that consumption of alcohol and illicit drugs hastens the onset of the disease. ${ }^{33}$

\section{Genetics}

A small proportion of patients presenting with $\mathrm{T} 2 \mathrm{D}$ ( $5 \%$ at all ages) have a monogenic, autosomal dominant form of T2D (maturity onset diabetes of the young (MODY), 1-6 subtypes). These patients generally have a strong family history of T2D in two or more consecutive generations. They generally show an early onset of chronic hyperglycaemia. For instance, subjects with glucokinase deficiency (MODY 2) present with mildly raised glucose values in the first week of life.

In contrast, MODY 3 subtype (due to mutation in the transcription factor hepatocyte nuclear factor $3 \alpha$ ) occurs at a later age, in general around or after puberty. ${ }^{34}$ In Caucasians, about 50\% of all MODY cases have mutations in glucokinase, and this condition is not infrequent in children with abnormal glucose values and absence of pancreatic islet antibodies. In adolescents and young adults with severe non-type 1 diabetes, MODY 3 is the most prevalent MODY gene.

Recently, several papers have described atypical forms T2D in children or adolescents with "private" mutations in HNF $1 \alpha .^{35-37}$ It is likely that besides HNFl, mutations in other key genes for $\beta$ cell phenotype may have the same effect when present at a high prevalence in isolated populations experiencing an obesity epidemic.

Apart from MODY, T2D is a multifactorial disease, dependent on the complex interaction of environmental and genetic factors with the effects of multiple genes. ${ }^{38} \mathrm{~A}$ well documented Danish twin study assessed genetic predisposition for T2D itself as $61 \%$, $26 \%$ for glucose intolerance, and $50 \%$ for an insulin secretory abnormality. ${ }^{39}$ In order to explain the higher incidence of T2D in diverse ethnicities, Neel proposed, in 1960, the thrifty genotype theory. Starvation selected genes efficient for energy storage, which are detrimental in affluent times, because of metabolic overload. ${ }^{40}$ At the present time, we are not aware of "original" thrifty genes in predisposed populations. The hypothesis of transethnically shared genes showing at-risk variants in a higher prevalence than in predisposed populations seems more likely. A recent example is the chromosome 2 NIDDM 1 CAP 10, encoding for the calpain 10 protease subtype. The same at-risk haplotype is present in more than $15 \%$ Mexican-Americans where it contributes to insulin resistance, compared to $<5 \%$ in Caucasians where its effect on diabetes risk is marginal. ${ }^{34}$

Whether adulthood and childhood onset T2D are genetically distinct entities remains unknown. Given the constant presence of obesity in patients with $\mathrm{T} 2 \mathrm{D}$, it is tempting to speculate that genes conferring a high risk for obesity in children may be the same as those linked to early onset T2D. In this regard VNTR promoter polymorphism in the insulin gene, which was known to be associated with low birth weight and with $\mathrm{T} 2 \mathrm{D}$, was recently shown to be also linked to both excess weight in the general population and to massive childhood obesity ${ }^{41}$ (P Froguel, unpublished data). Positional cloning strategies, which imply the genome scanning of dozens of families with multiple cases of children with severe obesity, and the mutation screening of candidate genes mapping to the regions of linkage will contribute to identify these genes, if they exist. ${ }^{34}$ A recent wide genome scan of French families with childhood obesity has mapped a chromosomal region linked to both insulin resistance and obesity on chromosome $6 \mathrm{q}$, at the same locus where a quantitative trait modulating glucose values was found in adults. ${ }^{42}$ The availability of large data sets of patients from various ethnic groups with early onset T2D will be necessary to search for susceptibility genes.

\section{THERAPEUTIC CONSEQUENCES}

Therapeutic interventions are based on the pathophysiology described above. Lifestyle changes, diet, ${ }^{43}$ and physical exercise, moderate but frequent, at least three times a week, ${ }^{44}$ constitute a prerequisite, but long term compliance is difficult to obtain in this age group. Oral medicines include insulin sensitisers and secretagogues. As a sensitiser, metformin (500 mg twice a day), compared to placebo, lowered fasting plasma glucose and $\mathrm{HbAlC}$ in adolescents with $\mathrm{T} 2 \mathrm{D}$, at the cost of transient abdominal discomfort and diarrhoea in some patients. ${ }^{45}$ Thiazolidinediones such as pioglitazone or rosiglitazone enhance insulin sensitivity in the liver, adipose tissue, and skeletal muscle. They reduce hepatic glucose output and increase muscle glucose uptake and can be used in combination with metformin, but age specific drug trials are needed.

Sulphonylurea insulin secretagogues act through binding to the $\beta$ cell membrane receptor, to stimulate insulin output. For decades young people with diabetes suffering from the monogenic form MODY 2 responded to chlorpropamide, one of the older analogues, ${ }^{46}$ but trials remain to be conducted for newer drugs such as glibenclamide and gliclazide in multifactorial T2D of the young. Prandial glucose regulators such as repaglinide are used to control post-prandial hyperglycaemia in adults. ${ }^{47}$ Oral combination therapy is more efficient than monotherapy in lowering $\mathrm{HbAlC}{ }^{48}$

Immediate insulin is required when there is significant ketonuria at presentation, and later if blood sugar control is inadequate with $\mathrm{HbAlC}$ levels $>7 \%$ in spite of intensive oral medication, dietary, and exercise management. ${ }^{49}$

Microvascular complications may be present from diagnosis in T2D. ${ }^{50}$ However, the aim is to achieve satisfactory blood glucose control, which may be difficult to adhere to in underprivileged minorities. ${ }^{51}$ Prevention of T2D through fighting obesity by reducing dietary fat intake and community led programmes to increase physical activity are political priorities for young people. The American "Diabetes Prevention Program Research Group" recently showed the efficacy of metformin and especially of physical activity in prevention of diabetes in T2D prone adults. ${ }^{52}$

Arch Dis Child 2004;89:502-505.

doi: 10.1136/adc.2003.028548

\section{Authors' affiliations}

J Weill, Paediatric Endocrine Unit, University Hospital, Lille, France

P Froguel, Institute of Biology-CNRS UMR 8090, Institut Pasteur de Lille, Lille, France $S$ Vanderbecken, Paediatric Department, Saint-François d'Assise Foundation, SaintDenis, Réunion Island, France

Correspondence to: Prof. P Froguel, Institute of Biology-CNRS 8090, Institut Pasteur de Lille, 1 rue Calmette, 59000 Lille, France; philippe. froguel@mail-good.pasteur-lille.fr

\section{REFERENCES}

\section{American Diabetes Association Expert} Committee. Reports of the Expert Committee on the Diagnosis and Classification of Diabetes Mellitus. Diabetes Care 1997;20:1183-97.

2 King M, Aubert RE, Herman WH. Global burden of diabetes 1995-2025: prevalence, numerical estimates, and projections. Diabetes Care 1998;21:1414-31.

3 Harris M, Flegal KM, Cowie CC, et al. Prevalence of diabetes, impaired fasting glucose and impaired glucose tolerance in US adults. The Third Health and Nutrition Examination Survey, 198894. Diabetes Care 1998;21:518-24. 
4 Bagust A, Hopkinson PK, Maier W, et al. An economic model of the long-term health care burden of type II diabetes. Diabetologia 2001:44:2140-55.

5 Campbell WR, Macleod JJR. Insulin. Medicine 1924;3:195-308

6 Eriksson J, Forsen B, Häggblom M, et al. Clinical and metabolic characteristics of type 1 and type 2 diabetes: an epidemiological study from the Närpes community in Western Finland. Diabet Med 1992:9:654-60.

7 Savage PJ, Bennett PM, Senter G, et al. High prevalence of diabetes in young Pima Indians. Evidence of phenotypic variation in a genetically isolated population. Diabetes 1979;28:837-42.

8 Pinhas-Hamiel O, Dolan LM, Daniels S, et al. Increased incidence of non-insulin-dependent diabetes mellitus among adolescents. J Pediatr 1996; 128:608-15.

9 Glaser NS, Jones KL. Non insulin dependent diabetes mellitus in Mexican American children. West J Med 1998;168:11-16.

10 Fagot-Campagna A, Pettit DI, Engelgau MM, et al. Type 2 diabetes among North American children and adolescents: an epidemiologic review and a public health perspective. J Pediatr $1999 ; 136: 664-72$

11 Fagot-Campagna A, Saadine JB, Flegal KM, et al. Impaired fasting glucose, and elevated $\mathrm{HbAlc}$ in US adolescents. The Third National Health and Nutrition Examination Survey. Diabetes Care $2001 ; 24: 834-7$

12 Sinha R, Fisch G, Teague B, et al. Prevalence of impaired glucose tolerance among children and adolescents with marked obesity. N Engl J Med 2002;346:802-10.

13 Kitagawa I, Owada M, Urakami I, et al. Increased incidence of non-insulin dependent diabetes mellitus among Japanese school children correlates with an increased intake of anima protein and fat. Clin Pediatr (Phila) 1998:37:111-16.

14 Ehtisham S, Barrett TG, Shaw NJ. Type 2 diabetes mellitus in UK children-an emerging problem. Diabet Med 2000;17:867-71.

15 Drake AJ, Smith A, Betts PR, et al. Type 2 diabetes in obese white children. Arch Dis Child 2002;86:207-8.

16 Rosenthal M, McMahan CA, Stern HP, et al. Evidence of bimodality of two hour plasma glucose concentrations in Mexican Americans: results from the San Antonio Heart Study. J Chron Dis 1985;38:5-16.

17 Arslanian S, Suprasongsin G, Janosky JE. Insulin secretion and sensitivity in black versus white prepubertal healthy children. J Clin Endocrinol Metab 1997;82:1923-7.

18 Danadian K, Lewy V, Janosky JJ, et al. Lipolysis in African-American children: is it a metabolic risk factor predisposing to obesity? J Clin Endocrinol Metab 2001;86:3022-6.

19 Arslanian S, Suprasongsin C. Differences in the in vivo insulin secretion and sensitivity of healthy black versus white adolescents. J Pediatr 1996; 129:440-3.

20 Sims EAM. Endocrine and metabolic effects of experimental obesity in man. Recent Progr Horm Res 1973;29:459-96.

21 Boden G. Obesity, free fatty acids, and insulin resistance. Curr Opin Diabetes Metab $2001: 8: 235-9$

22 Steppan CM, Lazar MA. Resistin and obesit associated insulin resistance. Trends Endocrinol Metab 2002;13:14-23.

23 Le Stunff C, Bougneres F. Early changes in postprandial insulin secretion, not insulin sensitivity characterize juvenile obesity. Diabetes 1995;43:696-702.

24 Sellers EA, Dean HJ. Diabetic ketoacidosis: a complication of type 2 diabetes in Canadian aboriginal youth. Diabetes Care 2000;23: 1202-4.

25 Hofman PI, Cutfield WS, Robinson EM, et al. Insulin resistance in short children with intrauterine growth retardation. J Clin Endocrinol Metab 1997;82:402-6

26 Lindsay RS, Hanson RL, Bennett PH, et al. Secular trends in birth weight, BMI, and diabetes in the offspring of diabetic mothers. Diabetes Care 2000;23:1249-54.

27 Goran MI, Gower BA. Longitudinal study on pubertal insulin resistance. Diabetes 2001;50:2444-50.

28 Acerini CL, Cheethan TD, Edge JA, et al. Both insulin sensitivity and insulin clearance in children and young adults with type 1 (insulin dependent) diabetes mellitus vary with growth hormone concentrations and with age. Diabetologia 2000;43:61-8.

29 Shillaber G, Lau DC. Regulation of new fat cell formation in rats. The role of dietary fat. J Lipid Res 1994;35:592-600.

30 Poitout V, Robertson RP. Mini review: secondary beta-cell failure in type 2 diabetes. A convergence of glucotoxicity and lipotoxicity. Endocrinology 2002;143:339-42.

31 Maclean PS, Zheng D, Jones JP, et al. Exerciseinduced transcription of the muscle glucose transporter (Glut 4) gene. Biochem Biophys Res Commun 2002;292:409-14.

32 Maffeis C, Zafanello M, Schutz A. Relationship between physical inactivity and adiposity in prepubertal boys. J Pediatr 1997; 131:288-92.

33 Johnson KM, Bazargan M, Cherpitel CJ. Alcohol, tobacco, and drug use and the onset of type 2 diabetes among inner-city minority patients. J Am Board Fam Pract 2001;14:430-6.

34 McCarthy M, Froguel P. Genetic approaches to the molecular understanding of type 2 diabetes. Am J Physiol 2002;283:E217-25.

35 Boutin P, Gresh L, Cisse A, et al. Missense mutation Gly574Ser in the transcription factor $\mathrm{HNF}$ - lalpha is a marker of atypical diabetes mellitus in African-American children. Diabetologia 1999;42:380-1.

36 Collet C, Ducorps M, Mayaudon $\mathrm{H}$, et al Prevalence of the missense mutation Gly574Ser in the hepatocyte nuclear factor-1 lalpha in Africans with diabetes. Diabetes Metab 2002;28:39-44

37 Triggs-Raine BL, Kirpatrick RD, Kelly SL, et al. HNFlalpha G319S, a transactivation-deficient mutant, is associated with altered dynamics of diabetes onset in Oji-Cree community. Proc Natl Acad Sci U S A 2002;99:4614-19.

38 Froguel P, Velho G. Genetic determinants of type 2 diabetes. Recent Progr Horm Res 2001;56:91-105.

39 Poulsen P, Kyvik KO, Vaag A, et al. Heritability of type 2 (non-insulin-dependent diabetes mellitus) and abnormal glucose tolerance-a populationbased twin study. Diabetologia 1999;42:139-45.

40 Neel JV. Diabetes mellitus: a thrifty genotype rendered detrimental by "progress"? Am J Hum Genet 1962;14:353-62.

41 Le Stunff C, Fallin D, Schork NJ, et al. The insulin gene VNTR is associated with fasting insulin levels and development of juvenile obesity. Nat Genet 2000;26:444-6.

42 Meyre D, Lecoeur G, Delplanque J, et al. A genome-wide scan for childhood obesityassociated traits in French families shows significant linkage on chromosome 6q22.31q23.2. Diabetes 2004;53:803-11

43 Hensrud PD. Dietary treatment and long-term weight loss and maintenance in type 2 diabetes. Obes Res 2001;9(suppl 4):348S-353S

44 Hamdy O, Goodyear L, Horton ES. Diet and exercise in type 2 diabetes mellitus. Endocrinol Metab Clin North Am 2001:30:883-907.

45 Jones KL, Arslanian S, Peterokova VA, et al. Effect of metformin in pediatric patients with type 2 diabetes: a randomized control trial. Diabetes Care 2002; 25:89-94.

46 Fajans S, Brown MB. Administration of sulfonylureas increases glucose-induced insulin secretion for decades in patients with maturityonset diabetes of the young. Diabetes Care 1993;16:1254-61.

47 Owens DR. Repaglinide: a new short-acting insulinotropic agent for the treatment of type 2 diabetes. Eur J Clin Invest 1999;29(suppl 2):30-7.

48 Inzucchi SE. Oral antihyperglycemic therapy for type 2 diabetes: scientific review. JAMA 2002;287:360-72

49 UK Prospective Diabetes Study (UKPDS) Group Intensive blood-glucose control with sulfonyl ureas or insulin compared with conventional treatment and risk of complications in patients with type 2 diabetes (UKPDS 33). Lancet 1998;352:837-53.

50 Fagot-Campagna A, Knowler WC, Pettit DS.

Type 2 diabetes in Pima Indian children. Cardiovascular risk factors at diagnosis and 10 years later. Diabetes 1998;47(suppl 1):A155

51 Delamater AM, Shaw KH, Applegate EB, et al. Risk for metabolic control problems in minority youth with diabetes. Diabetes Care 1999;22:700-5.

52 Diabetes Prevention Program Research Group. Reduction in the incidence of type 2 diabetes with lifestyle intervention or mefformin. $N$ Engl J Med 2002;346:393-403.

past 50 years over 400 hospital chaplains have been appointed. In pluralist societies, it is however essential that the spiritual needs of all faith communities are identified and met. ${ }^{2}$ Regrettably, this has not been the case with respect to many of the estimated three million Britons, or the one in ten children subscribing to non-Christian minority faith and ethnic communities. ${ }^{3}$

Acculturation-the process by which minority cultures gradually adopt the values and ethos of the majority culture-has for many families resulted in the erosion of traditional support networks. Such lay alliances have hitherto often been crucial buffers during times of illness, turmoil, and grief. And minority communities have, as has exists at the core of each and every being. ${ }^{1}$ So how, in modern day medical practice is this essential aspect of health catered for, for the children and their families from non-Christian faiths? "ovide" for the spiritual needs Britain staff. Almost every host 
repeatedly been shown by government reports on health inequalities, more than their fair share of morbidity and mortality, starting from the neonatal period and extending over the life course. ${ }^{4}$ It is therefore important that, as increasing demands are placed on chaplaincy services for support and advice, mechanisms are developed to ensure that such services are competent to cater for, and sensitive to the needs of, diverse populations.

Although some children from most religious backgrounds will have engaged in religious practices, in our experience this is particularly so with the South Asian and Jewish children who tend to absorb parental attitudes towards religion in the early years of their development without question or analysis. It is therefore important that children are given age and developmentally specific opportunities to share and explore their fears. Therefore in order to be effective, multi-faith chaplains must be aware of their own values, prejudices, and worldview as these will profoundly affect their response to cultures different from their own. Their service should, as a result, be flexible where individual needs are identified and accommodated, which is not possible with the present ad hoc system.

All children irrespective of background, deserve the right to receive care that helps them make sense of illness in the context of their life, and in so doing these children must be helped to live and die meaningfully in ways that are consistent with their own worldview. Experience suggests that despite the best of intentions, many of the current cohort of chaplains face difficulties in delivering spiritual care to those from non-Christian backgrounds. This is only to be expected since, in addition to the theological "gap", there is also often a lack of any in-depth appreciation of the workings of these "other" cultures.

It is now increasingly being recognised that all British chaplains need to undergo a broader training programme than hitherto in order to enable them to better fulfil a more generic chaplaincy role. But there still remains the issue of Christian chaplains often being unable to join in worship with patients of faiths other than their own, thereby limiting the potential to utilise the spiritual "tools" that a particular faith community will often employ in an attempt to restore a sense of balance and wellbeing. ${ }^{5}$

Symbolism is a universal religious phenomenon that has the potential to facilitate communion with an unseen
Reality. During times of uncertainty and spiritual pain, symbols such as incantations, sacred texts, and artefacts often assume heightened importance. Our experience suggests that this is certainly very true among the faiths practised by South Asian families in Britain. A bangle for a young Sikh boy (Kara), the family icon of a Hindu deity, and the Tawiz (a black string tied round the neck or wrist of a Muslim child) can all, if appropriately employed help provide comfort, hope, and an inner sense of peace. In contrast, lack of understanding of the role of such symbols can create misunderstanding and further turbulence in what are already trying times.

A wider appreciation of multicultural symbolism is only one example of the many ways in which cultural awareness and empathy can enhance delivery of health care. It is important for spiritual carers not only to be familiar with particular religious rites but also to be aware of the underlying narrative that threads these practices together.

Cultural competence is an evolving process that depends on self-reflection, self-awareness, and acceptance of differences. It is based on improving understanding, as opposed to an increase in cultural knowledge. ${ }^{6}$ Evidence indicates that training is much more likely to be effective if a "whole staff" or "systems" approach is taken. Implementation of culturally sensitive care and not mere tokenism must be the goal, and this is in our experience best achieved if all health practitioners involved with caring for children have the opportunity for appropriate training.

With the Department of Health and the Department of Education and Skills (DES) now pushing forward the agenda for developing a health and social care workforce through the NHS University (NHSU), this could be made possible from 2003. The NHSU has been set up as part of the NHS modernisation plan to provide practical learning and skills for everyone working in the health servicethat is, staff from all disciplines including carers and volunteers. ${ }^{7}$ Such an innovation can form part of a "continuous professional development" for "life long learning" for any section of the workforce.

We believe that this important development represents an excellent opportunity to incorporate generic issues on diversity and specific issues on faith into the training of chaplains so as to equip them with the requisite "insight" needed to facilitate and deliver multifaith care to the diverse populations they serve. This will perhaps be most effectively achieved by working in collaboration with existing training providers. For example, the Markfield Institute based in Loughborough University, which currently offers MA and PhD programmes for Muslim Imams wanting to become chaplains.

Inclusion of a question on religious affiliations in the 2001 Census allows us for the first time to accurately indicate geographical areas where particular religious groups are concentrated, for example, Hindus in Leicester, Muslims in Bradford, and Sikhs in Southall. It is therefore now possible to identify areas in which it would be sensible and feasible to employ specific faith chaplains.

The broken are often the bereaved, the sick, and the lonely. This is particularly so for those from cultures different from those in the west. Happiness is often heightened and tragedy lightened when shared with the family. It is in the understanding and meeting the needs of such people that spiritual "doctors" come into their own-whatever their faith, whatever their background.

Arch Dis Child 2004;89:504-505.

doi: 10.1136/adc.2003.044818

\section{Authors' affiliations}

A R Gatrad, Manor Hospital, Walsall, UK E Brown, Acorns Children Hospice Trust, Birmingham, UK

A Sheikh, Division of Community Health Sciences, GP Section, University of Edinburgh, Edinburgh, UK

Correspondence to: Dr A R Gatrad, Manor Hospital, Moat Road, Walsall WS2 9PS, UK; steadmana@walsallhospitals.nhs.uk

A Sheikh is Chairman of the Research and Development Committee of the Muslim Council of Britain

\section{REFERENCES}

1 Hinnells JR, Porter R. Religion, health and suffering. London: Keegan Paul, 1999.

2 Department of Health. The patient's charter London: DoH, 1999.

3 Rocheron Y, Dickinson R. The Asian mother and baby campaign: a way forward in health promotion for Asian women? Health Ed 1990;49:128-33.

4 National Statistics. Census 2001. Available at: http://www.statistics.gov.uk/census2001/ default.asp (accessed 24 May 2003).

5 Orchard H. Hospital chaplaincy: modern, dependable. The Lincoln Theological Institute. King's Fund London. Sheffield Academic Press, 2000:127-35.

6 Webb E, Sergison M. Evaluation of cultural competencies and antiracism training in child health. Arch Dis Child 2003;88:291-4.

7 NHSU. Learning for everyone (2003). Available at: http://www.nhsu.nhs.uk/what/_005.htm (accessed 30 October 2003). 